4

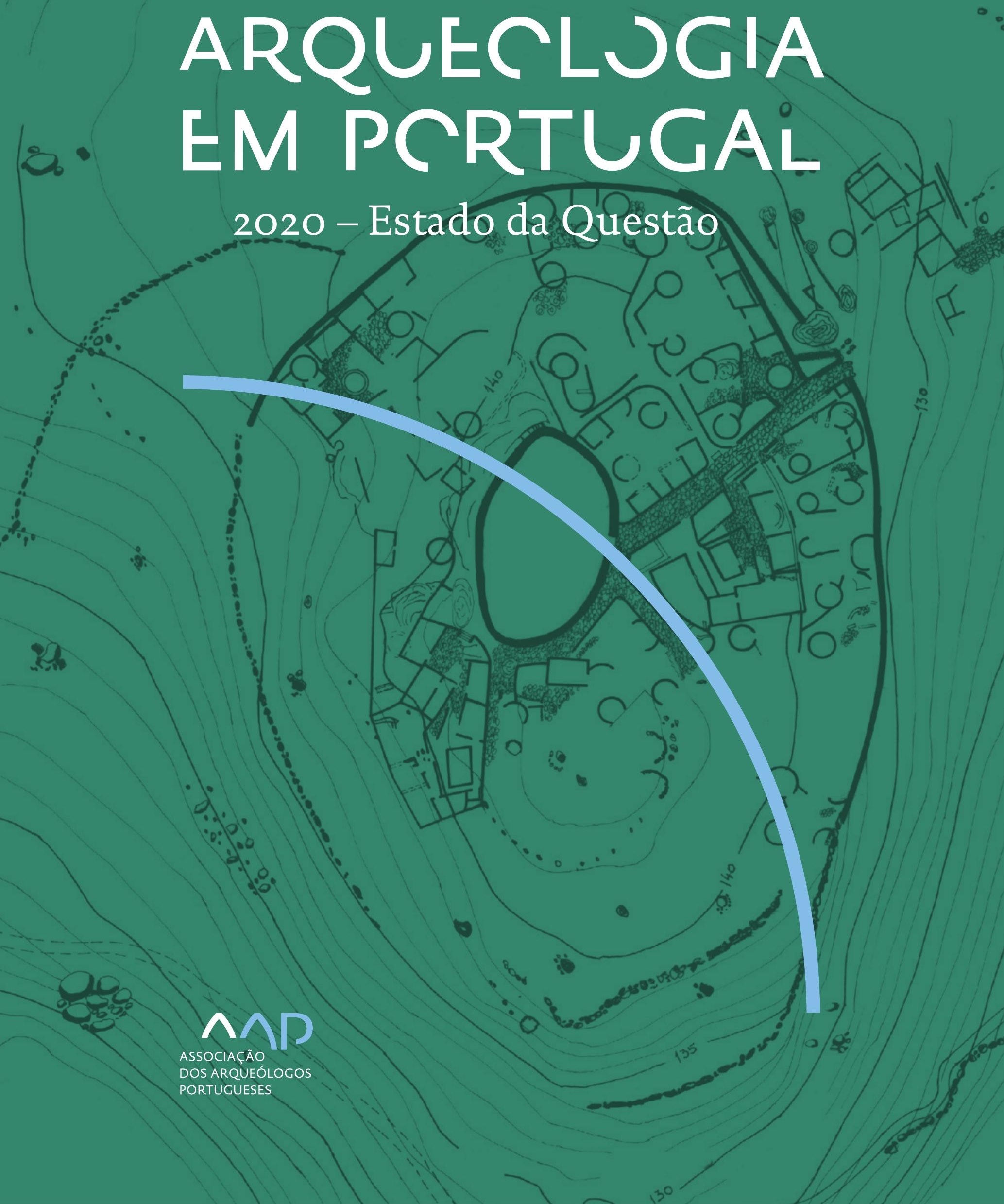


Coordenação editorial: José Morais Arnaud, César Neves e Andrea Martins Design gráfico: Flatland Design

AAP - ISBN: 978-972-9451-89-8

CITCEM - ISBN: 978-989-8970-25-1

Associação dos Arqueólogos Portugueses e CITCEM

Lisboa, 2020

O conteúdo dos artigos é da inteira responsabilidade dos autores. Sendo assim a Associação dos Arqueólogos Portugueses declina qualquer responsabilidade por eventuais equívocos ou questões de ordem ética e legal.

Desenho de capa:

Planta do castro de Monte Mozinho (Museu Municipal de Penafiel).

\section{$\hat{\wedge} \mathrm{P}$}

DOS ARQUEÓLOGOS PORTUGUESES

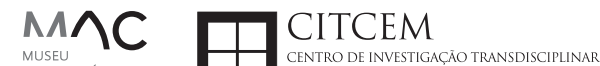
MUSEU
ARQUELLÓGICO
DO CARMO
U.PORTO

FLUP FACULDADE DE LETRAS
UNIVERSIDADE DO PORTO

Apoio

EC para a Ciência 


\section{Índice}

15 Prefácio

José Morais Arnaud

\section{Historiografia e Teoria}

17 Território, comunidade, memória e emoção: a contribuição da história da arqueologia (algumas primeiras e breves reflexões)

Ana Cristina Martins

25 Como descolonizar a arqueologia portuguesa?

Rui Gomes Coelho

41 Arqueologia e Modernidade: uma revisitação pessoal e breve de alguns aspetos da obra homónima de Julian Thomas de 2004

Vítor Oliveira Jorge

57 Dados para a História das Mulheres na Arqueologia portuguesa, dos finais do século XIX aos inícios do século XX: números, nomes e tabelas

Filipa Dimas / Mariana Diniz

73 Retractos da arqueologia portuguesa na imprensa: (in)visibilidades no feminino

Catarina Costeira / Elsa Luís

85 Arqueologia e Arqueólogos no Norte de Portugal Jacinta Bugalhão

101 Vieira Guimarães (1864-1939) e a arqueologia em Tomar: uma abordagem sobre o território e as gentes

João Amendoeira Peixoto / Ana Cristina Martins

115 Os memoráveis? A arqueologia algarvia na imprensa nacional e regional na presente centúria (2001-2019): características, visões do(s) passado(s) e a arqueologia

enquanto marca

Frederico Agosto / João Silva

129 A Evolução da Arqueologia Urbana e a Valorização Patrimonial no Barlavento Algarvio: Os casos de Portimão e Silves

Artur Mateus / Diogo Varandas / Rafael Boavida

\section{Gestão, Valorização e Salvaguarda do Património}

145 O Caderno Reivindicativo e as condições de trabalho em Arqueologia Miguel Rocha / Liliana Matias Carvalho / Regis Barbosa / Mauro Correia / Sara Simões / Jacinta Bugalhão / Sara Brito / Liliana Veríssimo Carvalho / Richard Peace / Pedro Peça / Cézer Santos

155 Os Estudos de Impacte Patrimonial como elemento para uma estratégia sustentável de minimização de impactes no âmbito de reconversões agrícolas Tiago do Pereiro

165 Salvaguarda de Património arqueológico em operações florestais: gestão e sensibilização Filipa Bragança / Gertrudes Zambujo / Sandra Lourenço / Belém Paiva / Carlos Banha / Frederico Tatá Regala / Helena Moura / Jacinta Bugalhão / João Marques / José Correia / Pedro Faria / Samuel Melro

179 Os valores do Património: uma investigação sobre os Sítios Pré-históricos de Arte Rupestre do Vale do Rio Côa e de Siega Verde José Paulo Francisco 
189 Conjugando recursos arqueológicos e naturais para potenciar as visitas ao Geoparque Litoral de Viana do Castelo (Noroeste de Portugal)

Hugo A. Sampaio / Ana M.S. Bettencourt / Susana Marinho / Ricardo Carvalhido

203 Áreas de Potencial Arqueológico na Região do Médio Tejo: Modelo Espacial Preditivo Rita Ferreira Anastácio / Ana Filipa Martins / Luiz Oosterbeek

223 Património Arqueológico e Gestão Territorial: O contributo da Arqueologia para a revisão do PDM de Avis

Ana Cristina Ribeiro

237 A coleção arqueológica do extinto Museu Municipal do Porto - Origens, Percursos e Estudos

Sónia Couto

251 Valpaços - uma nova carta arqueológica

Pedro Pereira / Maria de Fátima Casares Machado

263 Arqueologia na Cidade de Peniche

Adriano Constantino / Luís Rendeiro

273 Arqueologia Urbana: a cidade de Lagos como caso de Estudo Cátia Neto

285 Estratégias de promoção do património cultural subaquático nos Açores. O caso da ilha do Faial

José Luís Neto / José Bettencourt / Luís Borges / Pedro Parreira

297 Carta Arqueológica da Cidade Velha: Uma primeira abordagem

Jaylson Monteiro / Nireide Tavares / Sara da Veiga / Claudino Ramos / Edson Brito /

Carlos Carvalho / Francisco Moreira / Adalberto Tavares

311 Antropologia Virtual: novas metodologias para a análise morfológica e funcional Ricardo Miguel Godinho / Célia Gonçalves

\section{Didáctica da Arqueologia}

327 Como os projetos de Arqueologia podem contribuir para uma comunidade culturalmente mais consciente Alexandra Figueiredo / Claúdio Monteiro / Adolfo Silveira / Ricardo Lopes

337 Educação Patrimonial - Um cidadão esclarecido é um cidadão ativo! Ana Paula Almeida

351 A aproximação da Arqueologia à sala de aula: um caso de estudo no $3^{\circ}$ ciclo do Ensino Básico Luís Serrão Gil

363 Arqueologia 3.o - Pensar e comunicar a Arqueologia para um futuro sustentável Mónica Rolo

377 “Conversa de Arqueólogos" - Divulgar a Arqueologia em tempos de Pandemia Diogo Teixeira Dias

389 Escola Profissional de Arqueologia: desafios e oportunidades Susana Nunes / Dulcineia Pinto / Júlia Silva / Ana Mascarenhas

399 Os Museus de Arqueologia e os Jovens: a oferta educativa para o público adolescente Beatriz Correia Barata / Leonor Medeiros

411 O museu universitário como mediador entre a ciência e a sociedade: o exemplo da secção de arqueologia no Museu de História Natural e da Ciência da Universidade do Porto (MHNC-UP)

Rita Gaspar 
421 Museu de Lanifícios: Real Fábrica de Panos. Atividades no âmbito da Arqueologia Beatriz Correia Barata / Rita Salvado

427 Arqueologia Pública e o caso da localidade da Mata (Torres Novas) Cláudia Manso / Ana Rita Ferreira / Cristiana Ferreira / Vanessa Cardoso Antunes

431 Do sítio arqueológico ao museu: um percurso (também) didático Lídia Fernandes

447 Estão todos convidados para a Festa! E para dançar também... O projecto do Serviço Educativo do Museu Arqueológico do Carmo na $5^{\underline{a}}$ Edição da Festa da Arqueologia Rita Pires dos Santos

459 O “Clã de Carenque”, um projeto didático de arqueologia Eduardo Gonzalez Rocha

469 Mediação cultural: peixe que puxa carroça nas Ruínas Romanas de Troia Inês Vaz Pinto / Ana Patrícia Magalhães / Patrícia Brum / Filipa Santos

481 Didática Arqueológica, experiências do Projeto Mértola Vila Museu Maria de Fátima Palma / Clara Rodrigues / Susana Gómez / Lígia Rafael

\section{Arte Rupestre}

497 Os inventários de arte rupestre em Portugal Mila Simões de Abreu

513 O projeto FIRST-ART - conservação, documentação e gestão das primeiras manifestações de arte rupestre no Sudoeste da Península Ibérica: as grutas do Escoural e Maltravieso Sara Garcês / Hipólito Collado / José Julio García Arranz / Luiz Oosterbeek / António Carlos Silva / Pierluigi Rosina / Hugo Gomes / Anabela Borralheiro Pereira / George Nash / Esmeralda Gomes / Nelson Almeida / Carlos Carpetudo

523 Trabalhos de documentação de arte paleolítica realizados no âmbito do projeto PalæoCôa André Tomás Santos / António Fernando Barbosa / Luís Luís / Marcelo Silvestre / Thierry Aubry

537 Imagens fantasmagóricas, silhuetas elusivas: as figuras humanas na arte do Paleolítico Superior da região do Côa Mário Reis

$55^{1}$ Os motivos zoomórficos representados nas placas de tear de Vila Nova de São Pedro (Azambuja, Portugal) Andrea Martins / César Neves / José M. Arnaud / Mariana Diniz

571 Arte Rupestre do Monte de Góios (Lanhelas, Caminha). Síntese dos resultados dos trabalhos efectuados em 2007-2009 Mário Varela Gomes

599 Gravuras rupestres de barquiformes no Monte de S. Romão, Guimarães, Noroeste de Portugal Daniela Cardoso

613 Círculos segmentados gravados na Bacia do Rio Lima (Noroeste de Portugal): contributos para o seu estudo Diogo Marinho / Ana M.S. Bettencourt / Hugo Aluai Sampaio

631 Equídeos gravados no curso inferior do Rio Mouro, Monção (NW Portugal). Análise preliminar Coutinho, L.M. / Bettencourt, A.M.S / Sampaio, Hugo A.S

645 Paletas na Arte Rupestre do Noroeste de Portugal. Inventário preliminar Bruna Sousa Afonso / Ana M. S. Bettencourt / Hugo A. Sampaio 


\section{Pré-História}

661 O projeto Miño/Minho: balanço de quatro anos de trabalhos arqueológicos Sérgio Monteiro-Rodrigues / João Pedro Cunha-Ribeiro / Eduardo Méndez-Quintas / Carlos Ferreira / Pedro Xavier / José Meireles / Alberto Gomes / Manuel Santonja / Alfredo Pérez-González

677 A ocupação paleolítica da margem esquerda do Baixo Minho: a indústria lítica do sítio de Pedreiras 2 (Monção, Portugal) e a sua integração no contexto regional Carlos Ferreira / João Pedro Cunha-Ribeiro / Sérgio Monteiro-Rodrigues / Eduardo Méndez-Quintas / Pedro Xavier / José Meireles / Alberto Gomes / Manuel Santonja / Alfredo Pérez-González

693 O sítio acheulense do Plistocénico médio da Gruta da Aroeira Joan Daura / Montserrat Sanz / Filipa Rodrigues / Pedro Souto / João Zilhão

703 As sociedades neandertais no Barlavento algarvio: modelos preditivos com recurso aos SIG

Daniela Maio

715 A utilização de quartzo durante o Paleolítico Superior no território dos vales dos rios Vouga e Côa

Cristina Gameiro / Thierry Aubry / Bárbara Costa / Sérgio Gomes / Luís Luís / Carmen Manzano / André Tomás Santos

733 Uma perspetiva diacrónica da ocupação do concheiro do Cabeço da Amoreira (Muge, Portugal) a partir da tecnologia lítica Joana Belmiro / João Cascalheira / Célia Gonçalves

745 Novos dados sobre a Pré-história Antiga no concelho de Palmela. A intervenção arqueológica no sítio do Poceirão I

Michelle Teixeira Santos

757 Problemas em torno de Datas Absolutas Pré-Históricas no Norte do Alentejo Jorge de Oliveira

771 Povoamento pré-histórico nas áreas montanhosas do NO de Portugal: o Abrigo 1 de Vale de Cerdeira Pedro Xavier / José Meireles / Carlos Alves

783 Apreciação do povoamento do Neolítico Inicial na Baixa Bacia do Douro. A Lavra I (Serra da Aboboreira) como caso de estudo Maria de Jesus Sanches

797 O Processo de Neolitização na Plataforma do Mondego: os dados do Sector C do Outeiro dos Castelos de Beijós (Carregal do Sal)

João Carlos de Senna-Martinez / José Manuel Quintã Ventura / Andreia Carvalho / Cíntia Maurício

823 Novos trabalhos na Lapa da Bugalheira (Almonda, Torres Novas) Filipa Rodrigues / Pedro Souto / Artur Ferreira / Alexandre Varanda / Luís Gomes / Helena Gomes / João Zilhão

837 A pedra polida e afeiçoada do sítio do Neolítico médio da Moita do Ourives (Benavente, Portugal)

César Neves

857 Casal do Outeiro (Encarnação, Mafra): novos contributos para o conhecimento do povoamento do Neolítico final na Península de Lisboa.

Cátia Delicado / Carlos Maneira e Costa / Marta Miranda / Ana Catarina Sousa

873 Stresse infantil, morbilidade e mortalidade no sítio arqueológico do Neolítico Final/ Calcolítico ( $4^{\circ}$ e $3^{\circ}$ milénio a.C.) do Monte do Carrascal 2 (Ferreira do Alentejo, Beja) Liliana Matias de Carvalho / Sofia N. Wasterlain 
885 Come together: O Conjunto Megalítico das Motas (Monção, Viana do Castelo) e as expressões Campaniformes do Alto Minho Ana Catarina Basílio / Rui Ramos

899 Trabalhos arqueológicos no sítio Calcolítico da Pedreira do Poio Carla Magalhães / João Muralha / Mário Reis / António Batarda Fernandes

913 O sítio arqueológico de Castanheiro do Vento. Da arquitectura do sítio à arquitectura de um território João Muralha Cardoso

925 Estudo zooarqueológico das faunas do Calcolítico final de Vila Nova de São Pedro (Azambuja, Portugal): Campanhas de 2017 e 2018 Cleia Detry / Ana Catarina Francisco / Mariana Diniz / Andrea Martins / César Neves / José Morais Arnaud

943 As faunas depositadas no Museu Arqueológico do Carmo provenientes de Vila Nova de São Pedro (Azambuja): as campanhas de 1937 a 1967 Ana Catarina Francisco / Cleia Detry / César Neves / Andrea Martins / Mariana Diniz / José Morais Arnaud

959 Análise funcional de material lítico em sílex do castro de Vila Nova de S. Pedro (Azambuja, Portugal): uma primeira abordagem Rafael Lima

971 O recinto da Folha do Ouro 1 (Serpa) no contexto dos recintos de fossos calcolíticos alentejanos

António Carlos Valera / Tiago do Pereiro / Pedro Valério / António M. Monge Soares

\section{Proto-História}

987 Produção de sal marinho na Idade do Bronze do noroeste Português. Alguns dados para uma reflexão

Ana M. S. Bettencourt / Sara Luz / Nuno Oliveira / Pedro P. Simões / Maria Isabel C. Alves / Emílio Abad-Vidal

1001 A estátua-menir do Pedrão ou de São Bartolomeu do Mar (Esposende, noroeste de Portugal) no contexto arqueológico da fachada costeira de entre os rios Neiva e Cávado Ana M. S. Bettencourt / Manuel Santos-Estévez / Pedro Pimenta Simões / Luís Gonçalves

1015 O Castro do Muro (Vandoma/Baltar, Paredes) - notas para uma biografia de ocupação da Idade do Bronze à Idade Média

Maria Antónia D. Silva / Ana M. S. Bettencourt / António Manuel S. P. Silva / Natália Félix

1031 Do Bronze Final à Idade Média - continuidades e hiatos na ocupação de Povoados em Oliveira de Azeméis João Tiago Tavares / Adriaan de Man

1041 As faunas do final da Idade do Bronze no Sul de Portugal: leituras desde o Outeiro do Circo (Beja)

Nelson J. Almeida / Íris Dias / Cleia Detry / Eduardo Porfírio / Miguel Serra

1055 A Espada do Monte das Oliveiras (Serpa) - uma arma do Bronze Pleno do Sudoeste Rui M. G. Monge Soares / Pedro Valério / Mariana Nabais / António M. Monge Soares

1065 São Julião da Branca (Albergaria-a-Velha) - Investigação e valorização de um povoado do Bronze Final

António Manuel S. P. Silva / Paulo A. P. Lemos / Sara Almeida e Silva / Edite Martins de Sá

1083 Do castro de S. João ao Mosteiro de Santa Clara: notícia de uma intervenção arqueológica, em Vila do Conde Rui Pinheiro 
1095 O castro de Ovil (Espinho), um quarto de século de investigação - resultados e questões em aberto

Jorge Fernando Salvador / António Manuel S. P. Silva

1111 O Castro de Salreu (Estarreja), um povoado proto-histórico no litoral do Entre Douro e Vouga

Sara Almeida e Silva / António Manuel S. P. Silva / Paulo A. P. Lemos / Edite Martins de Sá

1127 Castro de Nossa Senhora das Necessidades (Sernancelhe): uma primeira análise artefactual Telma Susana O. Ribeiro

${ }_{1141}$ A cividade de Bagunte. O estado atual da investigação Pedro Brochado de Almeida

1153 Zoomorfos na cerâmica da Idade do Ferro no NW Peninsular: inventário, cronologias e significado Nuno Oliveira / Cristina Seoane

1163 Vasos gregos em Portugal: diferentes maneiras de contar a história do intercâmbio cultural na Idade do Ferro

Daniela Ferreira

1175 Os exotica da necrópole da Idade do Ferro do Olival do Senhor dos Mártires (Alcácer do Sal) no seu contexto regional

Francisco B. Gomes

\section{Antiguidade Clássica e Tardia}

1191 O uso de madeira como combustível no sítio da Quinta de Crestelos (Baixo Sabor): da Idade do Ferro à Romanização Filipe Vaz / João Tereso / Sérgio Simões Pereira / José Sastre / Javier Larrazabal Galarza / Susana Cosme / José António Pereira / Israel Espi

1207 Cultivos de Época Romana no Baixo Sabor: continuidade em tempos de mudança? João Pedro Tereso / Sérgio Simões Pereira / Filipe Santos / Luís Seabra / Filipe Vaz

1221 A casa romana na Hispânia: aplicação dos modelos itálicos nas províncias ibéricas Fernanda Magalhães / Diego Machado / Manuela Martins

1235 As pinturas murais romanas da Rua General Sousa Machado, n. ${ }^{5}$ 1, Chaves José Carvalho

1243 Trás do Castelo (Vale de Mir, Pegarinhos, Alijó) - Uma exploração agrícola romana do Douro

Tony Silvino / Pedro Pereira

1255 A sequência de ocupação no quadrante sudeste de Bracara Augusta: as transformações de uma unidade doméstica Lara Fernandes / Manuela Martins

1263 Os Mosaicos com decoração geométrica e geométrico-vegetalista dos sítios arqueológicos da área do Conuentus Bracaraugustanus. Novas abordagens quanto à conservação, restauro, decoração e datação Maria de Fátima Abraços / Licínia Wrench

1277 “Casa Romana” do Castro de São Domingos (Cristelos, Lousada): Escavação, Estudo e Musealização Paulo André de P. Lemos

1291 A arqueobotânica no Castro de Guifões (Matosinhos, Noroeste de Portugal): O primeiro estudo carpológico

Luís Seabra / Andreia Arezes / Catarina Magalhães / José Varela / João Pedro Tereso 
1305 Um Horreum Augustano na Foz do Douro (Monte do Castelo de Gaia, Vila Nova de Gaia) Rui Ramos

1311 Ponderais romanos na Lusitânia: padrões, formas, materiais e contextos de utilização Diego Barrios Rodríguez

1323 Um almofariz centro-itálico na foz do Mondego

Marco Penajoia

1335 Estruturas romanas de Carnide - Lisboa Luísa Batalha / Mário Monteiro / Guilherme Cardoso

1347 O contexto funerário do sector da "necrópole NO" da Rua das Portas de S. Antão (Lisboa): o espaço, os artefactos, os indivíduos e a sua interconectividade na interpretação do passado Sílvia Loja, José Carlos Quaresma, Nelson Cabaço, Marina Lourenço, Sílvia Casimiro, Rodrigo Banha da Silva, Francisca Alves-Cardoso

${ }_{1361}$ Povoamento em época Romana na Amadora - resultados de um projeto pluridisciplinar Gisela Encarnação / Vanessa Dias

1371 A Arquitectura Residencial em Mirobriga (Santiago do Cacém): contributo a partir de um estudo de caso Filipe Sousa / Catarina Felício

${ }_{1385}$ O fim do ciclo. Saneamento e gestão de resíduos nos edifícios termais de Mirobriga (Santiago do Cacém)

Catarina Felício / Filipe Sousa

1399 Balsa, Topografia e Urbanismo de uma Cidade Portuária Vítor Silva Dias / João Pedro Bernardes / Celso Candeias / Cristina Tété Garcia

1413 No Largo das Mouras Velhas em Faro (2017): novas evidências da necrópole norte de Ossonoba e da sua ocupação medieval Ricardo Costeira da Silva / Paulo Botelho / Fernando Santos / Liliana Nunes

1429 Instrumentos de pesca recuperados numa fábrica de salga em Ossonoba (Faro) Inês Rasteiro / Ricardo Costeira da Silva / Paulo Botelho

1439 A Necrópole Romana do Eirô, Duas Igrejas (Penafiel): intervenção arqueológica de 2016 Laura Sousa / Teresa Soeiro

1457 Ritual, descarte ou afetividade? A presença de Canis lupus familiaris na Necrópole Noroeste de Olisipo (Lisboa)

Beatriz Calapez Santos / Sofia Simões Pereira / Rodrigo Banha da Silva / Sílvia Casimiro / Cleia Detry / Francisca Alves Cardoso

1467 Dinâmicas económicas em Bracara na Antiguidade Tardia Diego Machado / Manuela Martins / Fernanda Magalhães / Natália Botica

1479 Cerâmicas e Vidros da Antiguidade Tardia do Edifício sob a Igreja do Bom Jesus (Vila Nova de Gaia) Joaquim Filipe Ramos

1493 Novos contributos para a topografia histórica de Mértola no período romano e na Antiguidade Tardia Virgílio Lopes

\section{8. Época Medieval}

1511 Cerâmicas islâmicas no Garb setentrional "português": algumas evidências e incógnitas Constança dos Santos / Helena Catarino / Susana Gómez / Maria José Gonçalves / Isabel Inácio / Gonçalo Lopes / Jacinta Bugalhão / Sandra Cavaco / Jaquelina Covaneiro / Isabel Cristina Fernandes / Ana Sofia Gomes 
1525 Contributo para o conhecimento da cosmética islâmica, em Silves, durante a Idade Média Rosa Varela Gomes

1537 Yábura e o seu território - uma análise histórico-arqueológica de Évora entre os séculos VIII-XII José Rui Santos

1547 A encosta sul do Castelo de Palmela - resultados preliminares da escavação arqueológica Luís Filipe Pereira / Michelle Teixeira Santos

1559 A igreja de São Lourenço (Mouraria, Lisboa): um conjunto de silos e de cerâmica medieval islâmica

Andreia Filipa Moreira Rodrigues

1571 O registo material de movimentações populacionais no Médio Tejo, durante os séculos XII-XIII. Dois casos de "sunken featured buildings", nos concelhos de Cartaxo e Torres Novas Marco Liberato / Helena Santos / Nuno Santos

1585 O nordeste transmontano nos alvores da Idade média. Notas para reflexão Ana Maria da Costa Oliveira

1601 Sepulturas escavadas na rocha do Norte de Portugal e do Vale do Douro: primeiros resultados do Projecto SER-NPVD

Mário Jorge Barroca / César Guedes / Andreia Arezes / Ana Maria Oliveira

1619 "Portucalem Castrum Novum" entre o Mediterrâneo e o Atlântico: o estudo dos materiais cerâmicos alto-medievais do arqueossítio da rua de D. Hugo, nํ. 5 (Porto) João Luís Veloso

1627 A Alta Idade Média na fronteira de Lafões: notas preliminares sobre a Arqueologia no Concelho de Vouzela

Manuel Luís Real / Catarina Tente

1641 Um conjunto cerâmico medieval fora de portas: um breve testemunho aveirense Susana Temudo

${ }_{1651}$ Os Lóios do Porto: uma perspetiva integrada no panorama funerário da Baixa Idade Média à Época Moderna em meios urbanos em Portugal

Ana Lema Seabra

1659 O Caminho Português Interior de Santiago como eixo viário na Idade Média Pedro Azevedo

1665 Morfologia Urbana: Um exercício em torno do Castelo de Ourém André Donas-Botto / Jaqueline Pereira

1677 Intervenção arqueológica na Rua Marquês de Pombal/Largo do Espírito Santo (Bucelas, Loures)

Florbela Estêvão / Nathalie Antunes-Ferreira / Dário Ramos Neves / Inês Lisboa

1691 O Cemitério Medieval do Poço do Borratém e a espacialidade funerária na cidade de Lisboa Inês Belém / Vanessa Filipe / Vasco Noronha Vieira / Sónia Ferro / Rodrigo Banha da Silva

1705 Um Espaço Funerário Conventual do séc. XV em Lisboa: o caso do Convento de São Domingos da Cidade Sérgio Pedroso / Sílvia Casimiro / Rodrigo Banha da Silva / Francisca Alves Cardoso

\section{9. Época Moderna e Contemporânea}

1721 Arqueologia Moderna em Portugal: algumas reflexões críticas em torno da quantificação de conjuntos cerâmicos e suas inferências históricas e antropológicas Rodrigo Banha da Silva / André Bargão / Sara da Cruz Ferreira

1733 Faianças de dois contextos entre os finais do século XVI e XVIII do Palácio dos Condes de Penafiel, Lisboa

Martim Lopes / Tomás Mesquita 
1747 Um perfil de consumo do século XVIII na foz do Tejo: O caso do Mercado da Ribeira, Lisboa Sara da Cruz Ferreira / Rodrigo Banha da Silva / André Bargão

1761 Os Cachimbos dos Séculos XVII e XVIII do Palácio Mesquitela e Convento dos Inglesinhos (Lisboa)

Inês Simão / Marina Pinto / João Pimenta / Sara da Cruz Ferreira / André Bargão / Rodrigo Banha da Silva

1775 "Tomar os fumos da erua que chamão em Portugal erua sancta». Estudo de Cachimbos provenientes da Rua do Terreiro do Trigo, Lisboa

Miguel Martins de Sousa / José Pedro Henriques / Vanessa Galiza Filipe

1787 Cachimbos de Barro Caulínitico da Sé da Cidade Velha (República de Cabo Verde)

Rodrigo Banha da Silva / João Pimenta / Clementino Amaro

1801 Algumas considerações sobre espólio não cerâmico recuperado no Largo de Jesus (Lisboa) Carlos Boavida

1815 Adereços de vidro, dos séculos XVI-XVIII, procedentes do antigo Convento de Santana de Lisboa (anéis, braceletes e contas)

Joana Gonçalves / Rosa Varela Gomes / Mário Varela Gomes

1837 Da ostentação, luxo e poder à simplicidade do uso quotidiano: arqueologia e simbologia de joias e adornos da Idade Moderna Portuguesa Jéssica Iglésias

1849 Os amuletos em Portugal - dos objetos às superstições: o coral vermelho Alexandra Vieira

1865 Cerâmicas de Vila Franca de Xira nos séculos XV e XVI Eva Pires

1879 «Não passa por teu o que me pertence». Marcas de individualização associadas a faianças do Convento de Nossa Senhora de Aracoeli, Alcácer do Sal Catarina Parreira / Íris Fragoso / Miguel Martins de Sousa

1891 Cerâmica de Leiria: alguns focos de produção

Jaqueline Pereira / André Donas-Botto

1901 Os Fornos na Rua da Biquinha, em Óbidos Hugo Silva / Filipe Oliveira

1909 A casa de Pêro Fernandes, contador dos contos de D. Manuel I: o sítio arqueológico da Silha do Alferes, Seixal (século XVI) Mariana Nunes Ferreira

1921 O Alto da Vigia (Sintra) e a vigilância e defesa da costa Alexandre Gonçalves / Sandra Santos

1937 O contexto da torre sineira da Igreja de Santa Maria de Loures Paulo Calaveira / Martim Lopes

1949 A Necrópole do Hospital Militar do Castelo de São Jorge e as práticas funerárias na Lisboa de Época Moderna Susana Henriques / Liliana Matias de Carvalho / Ana Amarante / Sofia N. Wasterlain

1963 SAND - Sarilhos Grandes Entre dois Mundos: o adro da Igreja e a Paleobiologia dos ossos humanos recuperados

Paula Alves Pereira / Roger Lee Jesus / Bruno M. Magalhães

1975 Expansão urbana da vila de Cascais no século XVII e XVIII: a intervenção arqueológica na Rua da Vitória no 15 a 17

Tiago Pereira / Vanessa Filipe

1987 Novos dados para o conhecimento do Urbanismo de Faro em época Moderna Ana Rosa 
1995 Um exemplo de Arqueologia Urbana em Alcoutim: o Antigo Edifício dos CTT Marco Fernandes / Marta Dias / Alexandra Gradim / Virgílio Lopes / Susana Gómez Martínez

2007 Palácio dos Ferrazes (Rua das Flores/Rua da Vitória, Porto): a cocheira de Domingos Oliveira Maia

Francisco Raimundo

2021 As muitas vidas de um edifício urbano: História, Arqueologia e Antropologia no antigo Recreatório Paroquial de Penafiel Helena Bernardo / Jorge Sampaio / Marta Borges

2035 O convento de Nossa Senhora da Esperança de Ponta Delgada: o contributo da arqueologia para o conhecimento de um monumento identitário João Gonçalves Araújo / N’Zinga Oliveira

2047 Arqueologia na ilha do Corvo... em busca da capela de Nossa Senhora do Rosário Tânia Manuel Casimiro / José Luís Neto / Luís Borges / Pedro Parreira

2059 Perdidos à vista da Costa. Trabalhos arqueológicos subaquáticos na Barra do Tejo Jorge Freire / José Bettencourt / Augusto Salgado

2071 Arqueologia marítima em Cabo Verde: enquadramento e primeiros resultados do projecto CONCHA

José Bettencourt / Adilson Dias / Carlos Lima / Christelle Chouzenoux / Cristóvão Fonseca / Dúnia Pereira / Gonçalo Lopes / Inês Coelho / Jaylson Monteiro / José Lima / Maria Eugénia Alves / Patrícia Carvalho / Tiago Silva

2085 Trabalhos arqueológicos na Cidade Velha (Ribeira Grande de Santiago, Cabo Verde): reflexões sobre um projecto de investigação e divulgação patrimonial André Teixeira / Jaylson Monteiro / Mariana Mateus / Nireide Tavares / Cristovão Fonseca / Gonçalo C. Lopes / Joana Bento Torres / Dúnia Pereira / André Bargão / Aurélie Mayer / Bruno Zélie / Carlos Lima / Christelle Chouzenoux / Inês Henriques / Inês Pinto Coelho / José Lima / Patrícia Carvalho / Tiago Silva

2103 A antiga fortificação de Quelba / Khor Kalba (E.A.U.). Resultados de quatro campanhas de escavações, problemáticas e perspectivas futuras Rui Carita / Rosa Varela Gomes / Mário Varela Gomes / Kamyar Kamyad

2123 Colónias para homens novos: arqueologia da colonização agrária fascista no noroeste ibérico Xurxo Ayán Vila / José Mạ . Señorán Martín 


\title{
O CADERNO REIVINDICATIVO E AS CONDIÇÕES DE TRABALHO EM ARQUEOLOGIA
}

Miguel Rocha ${ }^{1}$, Liliana Matias Carvalho² ${ }^{2}$, Regis Barbosa ${ }^{3}$, Mauro Correia ${ }^{4}$, Sara Simões ${ }^{5}$, Jacinta Bugalhão ${ }^{6}$, Sara Brito ${ }^{7}$, Liliana Veríssimo Carvalho ${ }^{8}$, Richard Peace ${ }^{9}$, Pedro Peça $^{10}$, Cézer Santos ${ }^{11}$

\begin{abstract}
RESUMO
Ser profissional de Arqueologia em Portugal significa, para a grande maioria, trabalhar sob um regime de precariedade e desregulação laboral, em condições pouco dignas e injustas. Neste sentido, a elaboração de um Caderno Reivindicativo para o trabalho em Arqueologia, como proposta concreta de discussão e de mobilização para a transformação e melhoria das condições de trabalho, constitui um eixo fundamental e prioritário da ação do STARQ - Sindicato dos Trabalhadores de Arqueologia. Por outro lado, ao apelar à discussão e participação das reivindicações formuladas, o STARQ procura ampliar o esclarecimento dos trabalhadores, criando entre eles um maior e mais forte sentido de organização e unidade, essenciais na conquista e garantia dos seus direitos. Palavras-chave: Setor laboral da Arqueologia, Atividade Sindical, Contratação Coletiva, Direito do Trabalho.
\end{abstract}

\begin{abstract}
Being an archaeology professional in Portugal means, for the vast majority, working under job insecurity and labour law deregulation, in unworthy and unfair working conditions. In this sense, the elaboration of a Caderno Reivindicativo (a list of demands) for work in Archaeology is a concrete proposal for discussion and mobilization towards change and improvement of working conditions. Therefore, it is a fundamental and urgent line of action for STARQ - The Portuguese archaeologists' union. By inviting others to discuss the announced claims, STARQ seeks to expand the understanding of workers' rights, creating among them a greater sense of organization and unity, essential to the achievement and warranty of their rights.

Keywords: Archeological setor, Workers rights, Union movement, Collective Labour Agreement, Labour Law.
\end{abstract}

\footnotetext{
1. STARQ; 1sd1514@gmail.com

2.STARQ; liliana_m_carvalho@yahoo.com.br

3.STARQ; regisbarbosa81@gmail.com

4.STARQ; maurocorreia_arq@outlook.pt

5.STARQ; saratsimoes@yahoo.com

6.STARQ; jacintabugalhao@gmail.com

7. STARQ; sarazenite@gmail.com

8. STARQ; verissimo.liliana@gmail.com

9. STARQ; richard.a.peace@gmail.com

10.STARQ; pedropeca@gmail.com

11.STARQ; cezer.santos@gmail.com
} 


\section{A PROFISSIONALIZAÇÃO DA ARQUEO- LOGIA EM PORTUGAL OU COMO PERCORRER O CAMINHO DAS PEDRAS}

O conceito de arqueólogo e, consequentemente de Arqueologia, em Portugal sofreu significativa evolução no decorrer do século XX (Bugalhão, 2017, p. 19). Evoluindo de uma espécie de hobby (amador), muitas vezes não remunerado, entrando paulatinamente no ordenamento jurídico português, até à atual situação onde a atividade é reconhecida como profissão, só acessível através de habilitação académica superior, e como disciplina científica devidamente enquadrada e regulamentada. Através do Decreto-Lei 164/2014 de 4 de Novembro (Regulamento de Trabalhos Arqueológicos), consideram-se aptas a dirigir trabalhos arqueológicos as pessoas academicamente habilitadas em Arqueologia, com prática profissional comprovada, especificando as condições da habilitação académica e a duração da experiência curricular.

Assim, a Arqueologia em Portugal, tal como noutras partes do mundo, passou por todas as fases de consolidação do pensamento arqueológico referidas por Renfrew e Bahn (1991), nomeadamente o amadorismo/coleccionismo, a academia, surgindo posteriormente a Arqueologia comercial. Podemos, conscientemente, falar de um amadurecimento da disciplina tal como da profissão.

Para além da evolução da profissão de arqueólogo, mais estudada, se recuarmos a 1893, data da abertura do Museu Etnográfico Português, pela mão de Leite de Vasconcelos, encontramos os primeiros trabalhadores em Arqueologia, a que se juntam os do quadro dos Serviços Geológicos (Bicho, 2006). No entanto, tendemos a esquecer os trabalhadores que hoje chamaríamos de "indiferenciados", que acompanharam as escavações promovidas desde Henri Breuil a Georges Zbyszewski, entre outros. Esses trabalhadores, usualmente locais e próximos dos sítios arqueológicos, tanto geográfica como emocionalmente, são veículos informais de informações arqueológicas. Com muita frequência, as suas memórias foram essenciais para reconstruir as intervenções arqueológicas daqueles que inscreveram o seu nome na disciplina ${ }^{12}$. Nos dias de hoje, estes trabalhadores seriam profissionais de Arqueologia e

12. Considerem-se os casos dos trabalhos arqueológicos promovidos por Manuel Heleno, Abel Viana e António Dias de Deus (Rolo, 2018; Wolfram, 2011). a sua vida, ganhando ao dia e provavelmente apenas durante uma parte do ano, não seria totalmente distante dos seus companheiros atuais.

O caminho para a profissionalização decorreu da consciencialização crescente sobre a importância do Património Cultural. A perspetiva de intervenção e regulamentação da salvaguarda e emergência arqueológica esteve subjacente à criação dos Serviços Regionais de Arqueologia em 1980 (Silva, 1995). Como refere o autor, "de um lado tínhamos toda uma nova geração de arqueólogos, recém saídos das Faculdades e fortemente motivados pela perspectiva de defesa do património, fenómenos que nos anos imediatos à Revolução do 25 de Abril conheceu efectiva expressão pública. Do outro, tínhamos vastas parcelas do território nacional que, face à retoma económica que se sucedeu à crise revolucionária, começavam a sofrer impactes significativos sobre o respectivo subsolo" (Silva, 1995, p. 98). Nesta fase inicial, a Arqueologia de salvaguarda era essencialmente assegurada pelos técnicos da administração central ou, mais raramente, local. No entanto, houve um crescimento do número de intervenções, fruto de um processo de que fizeram parte o extraordinário aumento da pressão de obras públicas sobre o território rural e os centros históricos (nos anos 90 do século XX), o processo de salvaguarda das gravuras do Côa (1994-1995), a criação do Instituto Português de Arqueologia (IPA) e a consequente ratificação da Convenção de Malta, em 1997.

Neste contexto surgiram as primeiras empresas de Arqueologia. Ainda no final dos anos 1990 tinha-se iniciado a construção da barragem do Alqueva, até hoje o maior projeto de Arqueologia preventiva em Portugal, que contribuiu para a consolidação da profissão de arqueólogo, do papel das empresas e da função fiscalizadora da administração central, já com o IPA. Nos primeiros anos das obras da barragem, empresas de Arqueologia recém-formadas trabalhavam lado a lado com equipas de investigação. Como refere António Carlos Silva "ainda que involuntariamente, o Projecto Arqueológico de Alqueva acabaria por contribuir de forma decisiva (...) para o florescimento da Arqueologia empresarial que se verificou em Portugal na transição do século" (2014, p. 21). Toda esta mudança na dinâmica do trabalho de Arqueologia não foi acompanhada da devida reflexão por parte de entidades públicas competentes, associações representativas e dos próprios trabalhadores, remetidos para um sistema laboral baseado 
na precariedade, ao qual a maioria só conseguia fugir abandonando a profissão.

Em pleno contexto da crise das dívidas soberanas, em 2012, um grupo de mais de 100 trabalhadores de Arqueologia achou ter chegado a um limite de desproteção laboral e de falta de perspetivas sobre as suas vidas futuras, assim avançaram com a criação do Sindicato dos Trabalhadores de Arqueologia (STARQ) (Mesquita \& Simões, 2014). Em 2020, o STARQ alcançou já uma representatividade muito significativa (superior a 10\% do universo global dos trabalhadores em Arqueologia), embora ainda com assimetrias regionais que se pretendem atenuar através da intensificação e disseminação do trabalho sindical. Considera-se por isso ser o momento para enfrentar os problemas estruturais da nossa realidade laboral, ou seja, identificar ruturas (com base num diagnóstico rigoroso) e promover soluções baseadas na lei e sustentáveis no tempo. O Caderno Reivindicativo é um instrumento e um referencial para o desenvolvimento do trabalho do sindicato nos próximos anos, quer junto das entidades públicas competentes, quer, principalmente, junto das entidades patronais privadas, nomeadamente as empresas de Arqueologia.

\section{DA PERTINÊNCIA E NECESSIDADE}

O trabalho em Arqueologia caracteriza-se pela sua desregulação: fragilidade dos vínculos laborais, precaridade, falta de condições de higiene, saúde e segurança e dificuldades acrescidas do trabalhador deslocado. O problema-base centra-se no regime laboral. As empresas que desenvolvem atividade no setor da Arqueologia e do Património suprem as suas necessidades de recursos humanos, essencialmente, através da aquisição de serviços e não, como deveriam, pela assinatura de contratos laborais. Ainda que as necessidades de postos de trabalho sejam permanentes, frequentemente as empresas preferem ocupá-los com trabalhadores em regime de prestação de serviços. A situação precária em que centenas de trabalhadores de Arqueologia se encontram, nomeadamente pela utilização abusiva e ilegal do recibo verde é assim uma realidade constante dos nossos dias, proporcionando condições de trabalho pouco dignas e injustas. Por outro lado, os valores praticados nos contratos de trabalho não se adequam à formação, responsabilidade e experiência pedida aos trabalhadores assalariados.
Os dados disponíveis apontam para que $75 \%$ dos profissionais exerce a profissão sob vínculos laborais precários, disfarçados de profissionais liberais (vulgo trabalhador independente/recibos verdes), ou com vínculos dependentes a prazo ou por tempo determinado (Bugalhão, 2017, p. 25). No que concerne aos rendimentos, em 2012, o rendimento médio anual de um arqueólogo em Portugal era $43 \%$ do rendimento médio dos técnicos superiores (APA, 2014, p. 76). A título de exemplo, o projeto DISCO 2014 constatou que cerca de metade dos arqueólogos não eram remunerados pelo tempo de trabalho despendido na elaboração de relatórios técnicos (APA, 2014, p. 87).

Assim, a experiência permite-nos facilmente constatar, infelizmente, que nem sempre a legislação existente e a sua aplicação respondem a estes problemas, observando-se, aliás, vazios legais. Nesse âmbito, a ação reivindicativa não só é o primeiro passo, como é um dos eixos prioritários do trabalho sindical. O Caderno Reivindicativo do STARQ procura regular o trabalho em Arqueologia, que se pretende abrangente e consensual entre os trabalhadores (através de um processo de discussão alargado) e de mobilização para a transformação e melhoria das condições laborais. As reivindicações propostas estão abertas à discussão e participação (segundo um calendário a divulgar) ampliando, também, o esclarecimento dos trabalhadores e o seu sentido de união.

\section{FUNÇÃO E OBJETIVOS}

No ordenamento jurídico português (Constituição, Código do Trabalho e demais legislação), a regulamentação coletiva de trabalho é o principal instrumento de regulação das relações laborais, competindo especialmente ao Estado a promoção da contratação coletiva, para que esta abranja o maior número possível de trabalhadores e empregadores. Assim, os contratos de trabalho devem ser preferencialmente regidos pela regulamentação coletiva de trabalho.

A Constituição da República Portuguesa (art.․5 56..) estabelece que o direito de negociação coletiva dos trabalhadores é exercido exclusivamente pelas associações sindicais. Nesse sentido, a partir de um adequado diagnóstico da situação pré-existente, o STARQ decidiu elaborar uma proposta de Caderno Reivindicativo. Este é um instrumento de promoção e defesa dos direitos dos trabalhadores, que visa a 
melhoria dos salários e a obtenção de direitos, com base nos princípios de igualdade e solidariedade, assim como a melhoria das condições de saúde, higiene e segurança no trabalho, sempre tendo em conta as especificidades do trabalho em Arqueologia.

O intuito fundamental do Caderno Reivindicativo é a resolução dos problemas individuais e coletivos dos trabalhadores, através da fixação de condições de trabalho que respeitem os seus direitos, com base em objetivos reivindicativos que reflitam as suas necessidades, com o propósito final de instituir um regime de trabalho mais favorável e equitativo, que contrarie a precariedade vigente.

A partir deste Caderno, a elaboração dos instrumentos de regulamentação coletiva de trabalho, e demais acordos, decorre de forma essencialmente negocial entre as partes, os sindicatos e os empregadores, de acordo com a Lei, em respeito pelo princípio da boa-fé. O Caderno Reivindicativo pode ainda ser visto como uma base justa para um contrato de trabalho em Arqueologia.

\section{PROBLEMÁTICAS LABORAIS ASSOCIA- DAS À ARQUEOLOGIA EMPRESARIAL}

As empresas de Arqueologia e Património não podem continuar a basear a sua atividade na prestação de serviços, na obtenção de lucro através do trabalho mal pago e pouco reconhecido de profissionais altamente qualificados. A situação precária em que centenas de trabalhadores se encontram, nomeadamente pela utilização abusiva e, muitas vezes ilegal, do recibo verde, é a prática comum, proporcionando condições de trabalho e de vida pouco dignas e injustas (STARQ, 2020a,b). Neste contexto, o preceito-base das reivindicações só pode ser este: o desempenho de funções permanentes deve dar lugar a vínculo efetivo, com os direitos legais daí decorrentes, que promovam a dignidade do trabalhador, a boa conciliação do trabalho com a vida familiar e pessoal, a expectativa de uma carreira profissional realizada e de consolidação crescente das suas condições económicas e sociais. Daí decorre a necessidade de se promover, entre outras medidas, a regularização dos vínculos precários. Como instrumento de combate à precariedade também é essencial a proposição de salários dignos, regulados e equitativos para todos os trabalhadores.

\section{REIVINDICAÇÕES FUNDAMENTAIS}

A primeira e principal reivindicação do Caderno refere-se à regularização dos vínculos precários, num justo equilíbrio entre o valor de recursos consignados às despesas de pessoal e às respeitantes a prestações de serviços. Neste âmbito o STARQ propõe: (i) adequação dos mapas de pessoal às necessidades das empresas; (ii) celebração de contratos por tempo indeterminado (efetivo ou sem termo) com os trabalhadores que desempenhem funções há dois ou mais anos ou que preencham necessidades permanentes; (iii) regularização dos vínculos precários e cessação do recurso ilegal a falsos recibos verdes, estágios, bolsas e trabalho de estudantes que asseguram tarefas que correspondem a necessidades permanentes; (iv) início de um processo negocial de regulamentação coletiva do trabalho a nível setorial ou empresarial, visando a vinculação e regularização dos trabalhadores precários, através do estabelecimento de objetivos calendarizados, com base no volume de trabalho de cada entidade.

Além do combate à precariedade é fundamental o reconhecimento da evolução profissional dos trabalhadores, configurada numa proposta de carreira que assegure conteúdos funcionais bem definidos e regras de progressão profissional claras, procurando a fixação de níveis salariais base para cada uma das categorias profissionais propostas. Neste sentido, o STARQ propõe o estabelecimento de níveis salariais base para cinco carreiras ${ }^{13}$ : Operário de Arqueologia, Técnico de Arqueologia, Arqueólogo Auxiliar, Arqueólogo Diretor e Arqueólogo Especialista. A progressão na carreira deverá ocorrer com base na antiguidade, no valor de $4 \%$ ao ano sobre o salário base da categoria.

Para a regulação do trabalho em Arqueologia é também fundamental o estabelecimento de garantias mínimas aos trabalhadores deslocados, determinando-se as necessárias obrigações da entidade patronal. O STARQ defende que: (i) a entidade patronal deve assumir diretamente, ou sob reembolso, o pagamento das despesas de deslocação; (ii) em alternativa, há lugar ao pagamento de todas as despesas de transporte e de ajudas de custo individuais (em valor a fixar); (iii) considerando a sazonalidade e a diferença de custo de vida entre as várias regiões

13. A mesma estrutura é aplicável a profissionais de outras áreas científicas que trabalhem no setor da Arqueologia. 
do país, quando este valor se revele insuficiente para cobrir a totalidade destes custos, deve ser garantido o pagamento integral e direto das despesas de alojamento e alimentação; no caso excecional de utilização de viatura própria, reclama-se o pagamento adicional de um subsídio de transporte por $\mathrm{Km}$, que cubra as despesas de combustível, e desgaste da viatura, bem como o pagamento de portagens, estacionamento, limpeza e lavagens e seguro automóvel para viagens (veículo, ocupante e terceiros).

Outro dos aspetos a regular é a duração das jornadas de trabalho e horário laboral. As formas de organização do trabalho em Arqueologia potenciam a flexibilidade e a autonomia, assim como a responsabilidade do trabalhador no desenvolvimento da sua prestação laboral. O acesso fácil à Internet transformou a atividade laboral, constituindo um meio de comunicação muito frequente e cada vez mais utilizado nas relações entre empregadores e trabalhadores. A facilidade de comunicação tem implicado, em várias situações, o trabalho fora do horário para a realização de tarefas de organização e partilha do registo arqueológico, bem como para a elaboração de documentos técnicos. As novas formas de comunicação apresentam características que desequilibram, potencialmente, a relação entre o tempo de vida profissional e o tempo de vida privada e familiar. Nesta perspetiva, salienta-se a necessidade de garantir certos direitos fundamentais, principalmente o direito à desconexão, ou seja, ao descanso, ao repouso e à integridade física e mental dos trabalhadores, bem como o necessário estabelecimento de limites ao controlo eletrónico do empregador. A este respeito o STARQ propõe: (i) um período normal de trabalho não superior a trinta e cinco horas em cada semana, nem a sete horas diárias; (ii) o direito a um intervalo para refeição ou descanso não inferior a uma nem superior a duas horas, não podendo os trabalhadores prestar mais de cinco horas seguidas de trabalho; (iii) o direito a uma pausa de 15 minutos em cada um dos períodos de trabalho diário (manhã e tarde), que conte para todos os efeitos como tempo de trabalho efetivo; (iv) o direito a dois dias de descanso semanal, gozados, em regra, em dias completos e sucessivos, ao sábado e ao domingo; (v) o direito à desconexão, ou seja, o direito a não atender chamadas, ler e/ou escrever mensagens de correio eletrónico, ler e/ou responder a mensagens de telemóvel ou a conversações em redes sociais, que estejam relacionadas com trabalho, fora do seu horário de trabalho; (vi) integração no horário de trabalho do tempo das deslocações para locais de trabalho a mais de $25 \mathrm{~km}$ de distância do posto de trabalho habitual; (vii) garantia de 24 horas de trabalho anuais remunerado para a realização de ações de divulgação científica, procurando responder ao exigido no Regulamento dos Trabalhos Arqueológicos.

O período normal de trabalho deve ser respeitado. Tudo o que está para lá do mesmo constitui-se como prestação de trabalho extraordinário, que, por isso mesmo, deve conferir a justa recompensa pelo esforço pessoal e familiar que acarreta. Neste sentido é necessário uma motivadora compensação do trabalho suplementar, bem como o pagamento do subsídio de turno, nos casos em que se justifiquem. Sobre trabalho extraordinário o STARQ propõe: (i) o pagamento do trabalho suplementar pelo valor da retribuição horária com acréscimo de $75 \%$ na primeira hora ou fração e $100 \%$ por hora ou fração subsequente, em dia útil e de $100 \%$ por cada hora ou fração, em dia de descanso semanal, obrigatório, complementar, ou feriado; (ii) a compensação do trabalho por turnos, caso se verifique, através de um subsídio de turno, a 50\% da respetiva remuneração base mensal, para o trabalho prestado em regime de três turnos e de laboração contínua com folga rotativa e a $35 \%$ da respetiva remuneração base mensal, para o trabalho prestado em regime de dois turnos e de laboração contínua com folga rotativa; (iii) o trabalho prestado entre as $20 \mathrm{~h}$ de um e as $8 \mathrm{~h}$ do dia seguinte seja considerado trabalho noturno, remunerado com um acréscimo de $50 \%$ da sua retribuição, por cada hora ou fração; (iv) obrigatoriedade de dispensa de trabalho noturno a partir dos 50 anos (desde que requerido).

A dificuldade de conciliação do trabalho com a vida familiar e pessoal, característica do trabalho em Arqueologia, é agravada pela precariedade e falta de regulação da atividade, com consequências nefastas na vida social, económica e pessoal dos profissionais. Por exemplo, nos índices sintéticos de fecundidade dos profissionais em Arqueologia, que se situava nos 0,5 por mulher e nos 0,7 nos homens, com uma média de o,6 que representa pouco mais de metade da média nacional que, em 2013, era de 1,03 (APA, 2014, p. 43-45), sendo apontados como os principais fatores para estes baixos índices os baixos rendimentos e a natureza do próprio trabalho (APA, 2014, p. 44).

É imperativo ter consciência desta realidade e pro- 
mover a sua correção, atenuando as disfunções verificadas. Com a existência a priori de direitos definidos, a dificuldade de mediação entre a esfera laboral e a pessoal e familiar será mais fácil. Assim, na elaboração do horário de trabalho, o STARQ considera que a entidade patronal deve ter em consideração as exigências de proteção da segurança e saúde do trabalhador, facilitando a conciliação da sua atividade profissional com a vida familiar e o acesso à educação (frequência de curso escolar ou académico) e à formação técnica ou profissional. A este propósito o STARQ propõe: (i) dispensa de progenitores com filhos menores, com deficiência ou doença crónica da prestação do trabalho noturno ou por turnos, através de requerimento para o efeito; (ii) organização de horários e formas de trabalho compatíveis para trabalhadores com filhos menores com deficiência ou doença crónica, idosos ou outros familiares que careçam de apoio; (iii) garantia de transporte para os trabalhadores na deslocação para o domicílio em condições de segurança, sempre que pratique um horário que não seja compatível com os transportes locais; (iv) o direito à prestação de assistência inadiável e imprescindível em caso de doença ou acidente de cônjuge ou pessoa que viva em união de facto ou economia comum com o trabalhador, parente ou afim em linha reta ou $2^{\circ}$ grau da linha colateral (em faltas justificadas).

A valorização profissional é um pilar incontornável da promoção da competência, eficácia e eficiência dos trabalhadores. A formação profissional, em particular, é um instrumento essencial para assegurar a transmissão, a análise e a concretização dos conhecimentos e da prática. $\mathrm{O}$ acesso à formação profissional (contínua) ao longo da vida é um dos direitos base do Código do Trabalho (Lei n.․ㄱ 7/2009, art. ${ }^{\circ} 130^{\circ}, 131^{\circ}, 132^{\circ}, 133^{\circ}$ e $134^{\circ}$, Diário da República n. ${ }^{\circ}$ 30/2009, Série I de 2009-02-12), contribui para a melhoria das competências dos trabalhadores e, consequentemente, para o aumento da qualidade do trabalho desenvolvido.

No atual panorama laboral a formação profissional contínua, em particular após a conclusão da licenciatura, é comum nos profissionais de Arqueologia, mas é realizada, sobretudo às expensas dos próprios (consequência da precariedade e falta de investimentos das entidades empregadoras) com os constrangimentos daí decorrentes. Em 2014 o cenário apresentado, não muito diferente do atual, revela que "a maioria dos arqueólogos inquiridos $(74,5 \%)$ afirmaram que fizeram ações de formação após a licenciatura, mas apenas $53,3 \%$ as mantém ao longo da sua atividade profissional (...); uma percentagem significativa $(21,8 \%)$ responde que nunca faz formação profissional contínua” (Disco, 2014, p. 52), o que constitui violação das obrigações das entidades empregadoras (Disco, 2014, p. 53-54). Neste âmbito, o STARQ propõe: (i) acesso à formação profissional de todos os trabalhadores, nomeadamente às 40 horas anuais, enquadrada em horário laboral; a formação profissional deve propiciar a formação contínua, técnica e científica dos trabalhadores, a aquisição de conhecimentos, designadamente na área das novas tecnologias, e da segurança, saúde e higiene no trabalho, bem como a introdução a novos mecanismos nas formas de trabalho; a elaboração de planos anuais de formação, discutidos e negociados com os trabalhadores, e as suas organizações representativas, que promovam a valorização das respetivas carreiras e desempenhos profissionais.

De igual modo, são necessárias condições mínimas de trabalho, que permitam exercer a profissão com dignidade e autonomia. É urgente providenciar boas condições de exercício profissional, nomeadamente no que diz respeito à segurança, saúde e higiene no trabalho e prevenção de doenças profissionais, garantindo-se a conformidade com os requisitos de segurança e de saúde aplicáveis. Refira-se a obrigatoriedade de cumprimento da legislação em vigor (Lei n.․102/2009, de 1o de Setembro) em matéria de prevenção da segurança, saúde e higiene no trabalho no que se refere à informação aos trabalhadores sobre as normas legais, convencionadas e regulamentadas correspondentes. Sobre segurança, saúde e higiene no trabalho o STARQ propõe: (i) identificar e prevenir os riscos previsíveis nas atividades desenvolvidas (inclusive antes da entrada das equipas de Arqueologia), por forma a eliminar ou reduzir a exposição a agentes de risco e aumentar os níveis de proteção; (ii) promover a formação e integrar os conhecimentos dos riscos para a segurança e saúde do trabalhador nos planos anuais de formação profissional; (iii) priorizar medidas de proteção coletiva e individual, adequadas aos equipamentos e materiais; (iv) promover a colaboração de todos os trabalhadores na realização e manutenção das melhores condições possíveis de segurança, higiene e saúde; (v) manter ou garantir instalações, equipamentos e locais de trabalho em condições de higiene e segurança, conforme as disposições legais em vigor, 
para que os trabalhadores se encontrem protegidos contra riscos de acidentes e doenças profissionais, garantindo a fiscalização das mesmas condições em cada local de trabalho, incluindo os trabalhos de Arqueologia prévios ao início das obras; (vi) sem prejuízo da existência de um refeitório geral, disponibilização aos trabalhadores de um local condigno, arejado e asseado, com mesas e cadeiras suficientes e equipado com os eletrodomésticos que sejam necessários à conservação e ao aquecimento de refeições ligeiras; (vii) garantia de locais de trabalho com os requisitos necessários e indispensáveis, incluindo a existência de vestiários, lavabos e balneários para uso dos trabalhadores, com condições de higiene e segurança; (viii) nos termos do Decreto-Lei n.. 53A/98 de 11 de Março, atribuição de um suplemento de risco, penosidade ou insalubridade, sempre que as condições de trabalho assim o exijam, nomeadamente em trabalhos arqueológicos em ambiente insalubres ou por fatores externos ou naturais que possam resultar em danos físicos ou psicológicos ao trabalhador; (ix) sempre que se verificarem temperaturas ambientais, medidas pelas entidades oficiais, mínimas abaixo de $5^{\circ} \mathrm{C}$ e máximas acima de $35^{\circ} \mathrm{C}$, o trabalhador ao ar livre deverá receber um subsídio de risco. Em alternativa poder-se-á optar pela redução ou adaptação do horário laboral, de modo a ajustar-se às melhores condições térmicas, sem prejuízo do trabalhador.

A maternidade e a paternidade constituem valores sociais incontestáveis. Nesse sentido, os trabalhadores têm direito à proteção da sociedade e do Estado no exercício da maternidade e paternidade. De forma a consagrar este entendimento, que infelizmente nem sempre se repercute nas relações laborais em Arqueologia (Simões et al., 2018, p. 112), até pelas características do regime laboral existente, o STARQ defende:

i. Licença em situação de risco clínico durante a gravidez, nos termos do art. ${ }^{\circ} 37$ da Lei n. ${ }^{\circ}$ 7/2009 (Código do Trabalho);

ii. Licença por interrupção de gravidez, nos termos do art.․․ 38 da Lei n.. $7 / 2009$ (Código do Trabalho);

iii. Licença parental exclusiva da mãe trabalhadora de até 30 dias antes do parto e obrigatória de seis semanas a seguir ao parto;

iv. Licença parental inicial de 120,150 ou 180 dias consecutivos a mãe e pai trabalhadores, cujo gozo podem partilhar após o parto, no respei- tante aos 150 ou 180 dias, sem prejuízo de outros direitos da mãe, completando a entidade patronal o subsídio parental inicial atribuído pela Segurança Social, de forma a garantir à mãe e pai trabalhadores o recebimento de $100 \%$ do seu vencimento base mensal. O gozo da licença pode ser usufruído em simultâneo pelos progenitores entre os 150 e os 180 dias e é acrescida em 30 dias, no caso de cada um dos progenitores gozar, em exclusivo, um período de 30 dias consecutivos, ou dois períodos de 15 dias consecutivos, após o período de gozo obrigatório pela mãe, referido no número anterior;

v. No caso de nascimentos múltiplos, o período de licença previsto no número anterior é acrescido de 30 dias por cada gémeo além do primeiro;

vi. Em caso de internamento hospitalar da criança ou do progenitor que estiver a gozar a licença parental inicial ou durante o período após o parto, o período de licença suspende-se, a pedido do progenitor, pelo tempo de duração do internamento;

vii. Licença parental exclusiva e obrigatória do pai de 20 dias úteis, seguidos ou interpolados, a seguir ao nascimento do filho, dez dos quais gozados de modo consecutivo imediatamente a seguir a este. Após o gozo desta licença, o pai tem ainda direito a 10 dias úteis de licença, seguidos ou interpolados, desde que gozados com a licença parental inicial da mãe. No caso de nascimentos múltiplos, à licença prevista acrescem dois dias por cada gémeo além do primeiro. A retribuição desta licença, na parte não subsidiada pela Segurança Social, será suportada pela entidade patronal;

viii. Licença por adoção, nos termos do art. ${ }^{\circ} 44 \mathrm{da}$ Lei n.. 7/2009 (Código do Trabalho);

ix. Licença parental complementar em qualquer das modalidades, nos termos do art. .51 da Lei n. ${ }^{\circ}$ 7/2009 (Código do Trabalho);

x. Dispensa da prestação de trabalho por parte de trabalhadora grávida, puérpera ou lactante, por motivo de proteção da sua segurança e saúde, nos termos do art. ${ }^{\circ} 62$ da Lei n. ${ }^{\circ}$ 7/2009 (Código do Trabalho);

xi. Dispensa para consultas pré-natais e de preparação para o parto da trabalhadora grávida e pai, pelo tempo e número de vezes necessários, 
devendo as mesmas consultas serem, sempre que possível, fora do horário de trabalho;

xii. Dispensa para avaliação para adopção, nos termos do art. ${ }^{\circ} 4$ da Lei n. ${ }^{\circ}$ 7/2009 (Código do Trabalho);

xiii. Dispensa diária para amamentação ou aleitação da mãe, durante o tempo que durar a amamentação, gozada em dois períodos distintos, com a duração de uma hora cada e de acordo com o interesse da criança, salvo se outro regime mais favorável for acordado com a empresa. Sendo que, no caso de não haver amamentação, desde que ambos os progenitores exerçam atividade profissional, qualquer deles ou ambos, consoante decisão conjunta, têm direito a dispensa para aleitação, até o filho perfazer um ano. No caso de nascimentos múltiplos, a dispensa referida é acrescida de mais 30 minutos por cada gémeo além do primeiro;

xiv. Direito a faltar ao trabalho para assistência, inadiável e imprescindível, a filho menor, a filho com deficiência ou com doença crónica, em caso de doença ou acidente, até 30 dias por ano ou durante todo o período de eventual hospitalização, completando a entidade patronal o subsídio atribuído pela Segurança Social, de forma a garantir à mãe e pai trabalhadores o recebimento de $100 \%$ do seu vencimento base mensal;

xv. Faltas para assistência a neto, nos termos do art. ${ }^{\circ} 50$ da Lei n. ${ }^{\circ}$ 7/2009 (Código do Trabalho);

xvi. Licença para assistência a filho, nos termos do art. ${ }^{\circ} 2$ da Lei n.. 7/2009 (Código do Trabalho);

xvii. Licença para assistência a filho com deficiência ou doença crónica, nos termos do art. ${ }^{\circ} 53$ da Lei n. ${ }^{\circ}$ 7/2009 (Código do Trabalho);

xviii. Horário flexível ${ }^{14}$ ou trabalho a tempo parcial $^{15}$ de trabalhador com responsabilidades

\footnotetext{
14. Entende-se por horário flexível aquele em que o trabalhador pode escolher, dentro de certos limites, nomeadamente o de estar enquadrado dentro do horário de funcionamento da empresa ou serviço, as horas de início e termo do período normal de trabalho diário.

15. O período normal de trabalho a tempo parcial corresponde a metade do praticado a tempo completo numa situação comparável e, conforme o pedido do trabalhador, é prestado diariamente, de manhã ou de tarde, ou em três dias por semana.
}

familiares (com filho menor de 12 anos ou, independentemente da idade, filho com deficiência ou doença crónica que com ele viva em comunhão de mesa e habitação);

xix. Dispensa de prestação de trabalho em regime de adaptabilidade, nos termos do art. $.58 \mathrm{da}$ Lei n. ${ }^{\circ}$ 7/2009 (Código do Trabalho);

xx. Dispensa de prestação de trabalho suplementar da trabalhadora grávida, lactante e o/a trabalhador/a com filho menor;

xxi. Dispensa de prestação de trabalho no período noturno ou por turnos da trabalhadora grávida, lactante e o/a trabalhador/a com filho menor;

xxii. Direito da trabalhadora grávida, puérpera ou lactante a especiais condições de segurança e saúde nos locais de trabalho, de modo a evitar a exposição a riscos para a sua segurança e saúde. Sem prejuízo de outras obrigações previstas em legislação especial, em atividade susceptível de apresentar um risco específico de exposição a agentes, processos ou condições de trabalho, a entidade patronal deve proceder à avaliação da natureza, grau e duração da exposição de trabalhadora grávida, puérpera ou lactante, de modo a determinar qualquer risco para a sua segurança e saúde e as repercussões sobre a gravidez ou a amamentação, bem como as medidas a tomar;

xxiii. O despedimento de trabalhadora grávida, puérpera ou lactante ou de trabalhador no gozo de licença parental carece de parecer prévio da entidade competente na área da igualdade de oportunidades entre homens e mulheres (CITE), presumindo-se feito sem justa causa o despedimento por facto imputável a trabalhador que se encontre em qualquer das situações referidas.

\section{CONCLUSÕES}

O caminho a percorrer na negociação do Contrato Coletivo é longo e muito exigente. Depois de concluída a primeira versão do Caderno Reivindicativo, será apresentado a todos os associados do STARQ, para efeitos de debate e recolha de contributos, processo que será seguidamente alargado a toda a comunidade arqueológica. Finalizado o Caderno Reivindicativo e, com base neste, o STARQ iniciará um período de negociação com as empresas e entidades 
patronais. Nessa fase, os trabalhadores serão chamados a desempenhar um papel ativo e crítico na discussão, defesa e negociação dos seus direitos, bem como na reflexão sobre a forma como está estruturada a atividade em Arqueologia. Este momento exigirá uma atitude solidária e coletiva, na procura de relações profissionais justas, equitativas, democráticas e igualitárias.

\section{BIBLIOGRAFIA}

APA (2014) - DISCO. Discovering the Archaeologists of Portugal 2012-14. Associação Profissional de Arqueólogos, 149 p. Disponível em: https://www.discovering-archaeologists. eu/national_reports/2014/PT\%20DISCO\%202014\%2O Portugal\%2onational\%2oreport\%2oportuguese.pdf (acedido em 18 de maio de 2018).

BICHO, Nuno Ferreira (2006) - Manual de Arqueologia Pré-Histórica. Edições 7o, p. 53.

BUGALHÃO, Jacinta (2017) - O papel da mulher na arqueologia portuguesa. Ophiussa.Lisboa, 1, pp. 123-13o. Disponível em: http://ophiussa.letras.ulisboa.pt/article/TmcgPQ\# (acedido em em 18 de maio de 2018).

BUGALHÃO, Jacinta (2017) - Arqueólogos Portugueses. In ARNAUD, José Morais; MARTINS, Andrea, eds. - ArqueologiaemPortugal/2017-Estadoda Questão.Lisboa: Associação dos Arqueólogos Portugueses, pp. 19-31. Disponível em: http://museuarqueologicodocarmo.pt/publicacoes/outras_publicacoes/II_congresso_aap_actas.pdf (acedido em 18 de maio de 2018).

MESQUITA, Ana; SIMÕES, Sara (2014) - Os Trabalhadores de Arqueologia Portugueses já têm um Sindicato. Al-madan online. Almada. II Série, 19 (1), pp. 197-198. Disponível em: https://issuu.com/almadan/docs/al_madanonline19_1 (acedido em 18 de maio de 2018).

RENFREW, Colin; BAHN, Paul (1991) - Archaeology. Theories, Methods and Practice. Londres: Thames and Hudson, $543 \mathrm{p}$.

ROLO, Ana Mónica da Silva (2018) - O mundo funerário romano no Noroeste Alentejano (Portugal): o contributo das intervenções de Abel Viana e António Dias de Deus. Tese de doutoramento em Arqueologia apresentada à Faculdade de Letras da Universidade de Lisboa. Disponível em: https:// repositorio.ul.pt/bitstream/10451/37249/1/ulfl257354_ td_Vol\%2oI.pdf (acedido em Junho de 220).

SILVA, António Carlos (1995) - Arqueologia Preventiva e de Salvaguarda: a ponta do iceberg. Al-madan. Almada. II Série, 4, pp. 97-10o.

SIMÕES, Sara; BRITO, Sara; CARVALHO, Liliana; BUGALHÃO, Jacinta; MOREIRA, Andreia (2018) - Questões de Género em Contexto Laboral em Arqueologia: breves notas. Al-madan online. Almada. II Série, 22 (2), pp. 111-113.
Disponível em: https://issuu.com/almadan/docs/al-madanonline22_2 (acedido em 18 de maio de 2018).

COMISSÃO IGUALDADE MULHERES E HOMENS (2018) - Caracterização e dados sobre as desigualdades das mulheres no trabalho (discriminação salarial, precariedade, conciliação, maternidade/paternidade, assédio, doenças profissionais). CGTP. Disponível em http://www.cgtp.pt/ images/images/2018/o3/mulheresnotrabalho.pdf (acedido em 18 de maio de 2018).

STARQ, 2020a - Pandemia COVID-19. Impacto laboral em Arqueologia. Resultados de inquérito submetido à comunidade de trabalhadores de arqueologia (entre 21 e 31 de Março de 2020). STARQ. Disponível em: http://starq.info/ wp_direc/wp-content/uploads/2020/o4/COVID-Inqu\% $\mathrm{C}_{3} \%$ Agrito-Relat\% $\mathrm{C}_{3} \%$ B 3 rio.pdf (acedido em 25 de Junho de 2020).

STARQ, 2020b - Pandemia COVID-19. Impacto laboral em Arqueologia. Resultados de inquérito submetido à comunidade de trabalhadores de arqueologia (entre 8 e 25 de Maio de 2020). STARQ. Disponível em: http://starq.info/ wp_direc/wp-content/uploads/2020/o7/COVID_Inqu\% $\mathrm{C}_{3} \%$ Agrito-2_-Relat\% $\mathrm{C}_{3} \%$ B3rio_final.pdf (acedido em 9 de Julho de 2020).

WOLFRAM, Mélanie (2011) - Uma síntese sobre a cristianização do mundo rural no sul da Lusitania: arqueologia-arquitectura-epigrafia. Tese de doutoramento em Arqueologia apresentada à Faculdade de Letras da Universidade de Lisboa. Disponível em: https://repositorio.ul.pt/bitstream/10451/5678/3/ullsdo62156_td_tese.pdf(acedido em Junho de 2020). 


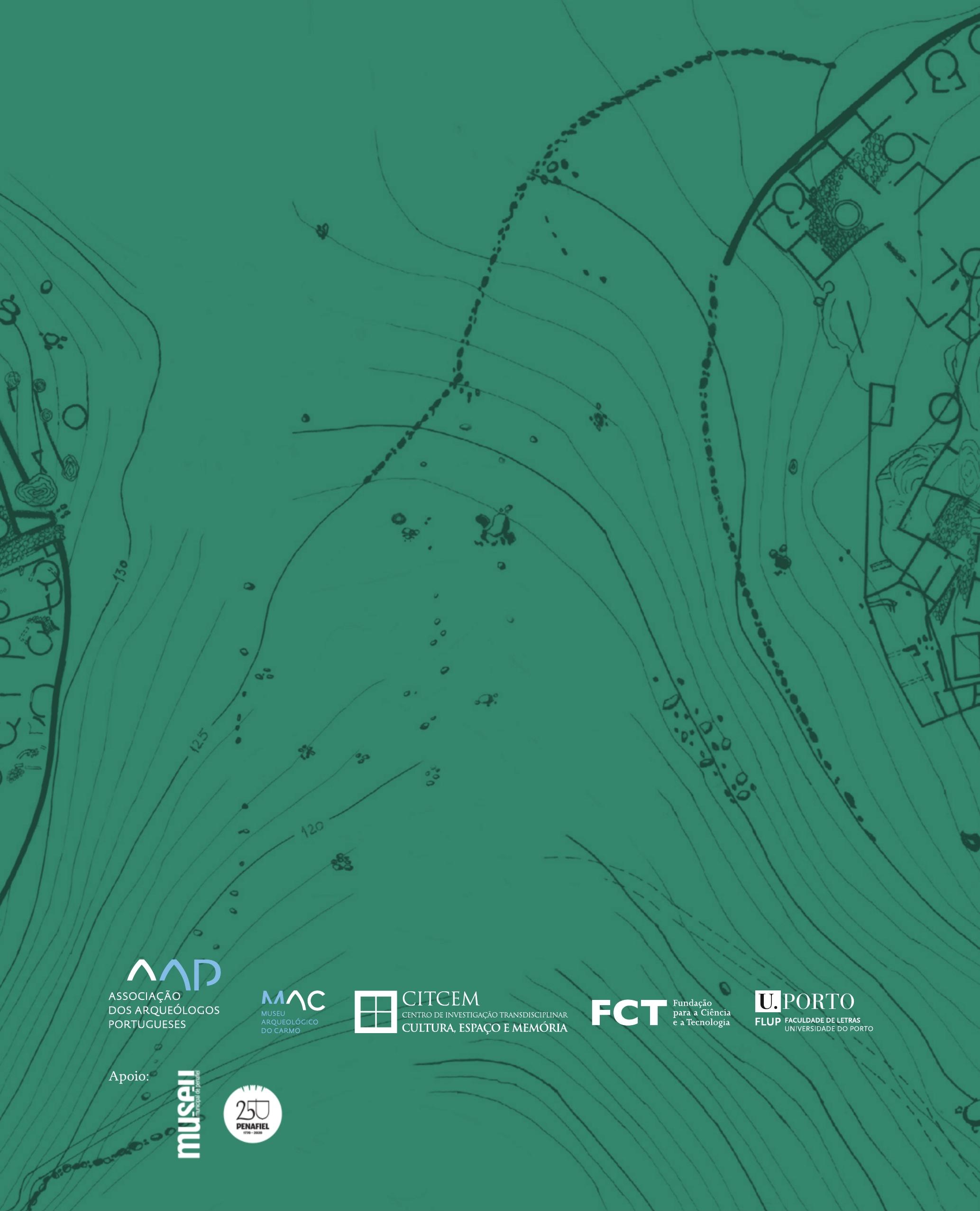

